\section{Policy Research Working Paper}

\section{Optimal Use of Carbon Sequestration in a Global Climate Change Strategy}

Is there a Wooden Bridge to a Clean Energy Future?

Franck Lecocq

Kenneth Chomitz
WPS 2635

2635

Does temporary sequestration of carbon dioxide have a place in a comprehensive policy for mitigating climate change? Does it "buy time" for technical change in the energy sector?

The World Bank

Development Research Group Infrastructure and Environment July 2001 
Policy Research Working Paper 2635

\section{Summary findings}

Carbon sequestration aims at raising the amount of carbon sequestered in biomass and in soils. Whether it should be part of a global climate mitigation strategy, however, remains controversial.

One of the key issues is that, contrary to emission abatement, carbon sequestration might not be permanent. But some argue that even temporary sequestration is beneficial as it delays climate change impacts and "buys" time for technical change in the energy sector.

To rigorously assess these arguments, Lecocq and Chomitz build an intertemporal optimization model in which both sequestration and abatement can be used to mitigate climate change.

They confirm that permanent sequestration, if feasible, can be an overall part of a climate mitigation strategy. When permanence can be guaranteed, sequestration is equivalent to fossil-fuel emissions abatement.

The optimal use of temporary sequestration, on the other hand, depends mostly on marginal damages of climate change. Temporary sequestration projects starting now, in particular, are not attractive if marginal damages of climate change at current concentration levels are assumed to be low.

This paper-a product of Infrastructure and Environment, Development Research Group-is part of a larger effort in the group to assess policies for mitigating climate change. Copies of the paper are available free from the World Bank, 1818 H Street NW, Washington, DC 20433. Please contact Viktor Soukhanov, room MC2-523, telephone 202-473-5721, fax 202-522-3230, email address vsoukhanov@worldbank.org. Policy Research Working Papers are also posted on the Web at http://econ.worldbank.org. The authors may be contacted at flecocq@worldbank.org or kchomitz@worldbank.org. July 2001. (27 pages)

The Policy Research Working Paper Series disseminates the findings of work in progress to encourage the exchange of ideas about development issues. An objective of the series is to get the findings out quickly, even if the presentations are less than fully polished. The papers carry the names of the authors and should be cited accordingly. The findings, interpretations, and conclusions expressed in this paper are entirely those of the authors. They do not necessarily represent the view of the World Bank, its Executive Directors, or the countries they represent. 


\title{
Optimal Use of Carbon Sequestration in a Global Climate Change Strategy: Is there a Wooden Bridge to a Clean Energy Future?
}

\author{
Franck Lecocq ${ }^{*}$, Kenneth Chomitz \\ July 2001 \\ World Bank, Development Economic Research Group, Infrastructure and Environment \\ 1818 H St NW Washington DC 20433 USA
}

\section{Introduction}

Does temporary sequestration of $\mathrm{CO}_{2}$ have a place in a comprehensive policy for mitigating climate change? Three arguments have been advanced in favor of sequestration. First, some proportion of "temporary" sequestration may prove permanent (Chomitz, 2000). This applies both for plantations, which may become financially sustainable after initial barriers such as establishment costs have been overcome, and for deforestation prevention projects in areas where pressure on forest turns out to be only temporary ${ }^{1}$. Second, temporary sequestration may succeed in deferring climatic damages, and this deferral is argued to be a benefit. Third, some argue that temporary sequestration "buys time" for technical change: in other words, it bridges from a period when energy abatement is expensive to a future

\footnotetext{
Corresponding author: flecocq@worldbank.org, Tel: +1-202-473-1231, Fax: +1-202-522-3230. The findings, interpretations, and conclusions expressed in this paper are entirely those of the authors. They do not necessarily represent the view of the World Bank, its Executive Directors, of the countries they represent.

${ }^{1}$ Examples of Europe, the US, Puerto Rico or Malaysia suggest that there is a "high tide" of forest clearance at moderate levels of development, which recedes as farmers are pulled from forest margins to urban jobs (such "deforestation Kuznets curves" can be found for example in Vincent et al., 1997). Worldwide, land-use projections show a declining rate of agricultural expansion over the next 30 years (FAO, 2000a). As a result, temporary (30 year) protection might end up as de facto permanent.
} 
era when alternative energy sources are cheap (Schwarze and Niles, 2000, Noble and Scholes, 2001). The present paper aims at rigorously assessing these arguments.

Temporary sequestration delays emissions with regard to the baseline. The key issue is therefore to know whether energy abatement and permanent sequestration can be reorganized in such a way that the total costs of the climate policy - damages plus abatement costs - diminish enough to offset the costs of the temporary sequestration project. To answer this question, we build a long term climate policy optimization model in which the planner has both the possibility to abate fossil-fuel emissions and to sequester carbon, either temporarily or permanently (section 2). In this model, we consider only deforestation prevention projects, which appear to be inexpensive and to offer potentially important side benefits such as biodiversity conservation, watershed protection and improvement of rural livelihoods when alternatives to deforestation are offered (Chomitz, 2000).

In section 3, we first apply the model to the class of permanent deforestation prevention projects. We demonstrate that sequestration and emissions reduction from fossil fuel combustion should then be considered similarly -marginal costs should be equated - provided spatial externalities are negligible. In section 4, we turn to temporary deforestation prevention projects, and show these are not cost-effective in the short and medium run unless marginal damages of climate change are high enough. We next combine both possibilities in a model where the planner has the choice to keep deforestation prevention running or to terminate it at each point of time. Both analytically (section 5) and numerically (section 6), marginal damages at low concentration levels prove again critical for the optimal sequestration patterns section. We demonstrate the results obtained for deforestation prevention can be generalized to plantations in section 7 .

\section{A climate policy optimization model with emission abatement and deforestation prevention}

Let a planner optimize long term world climate policy so as to minimize total costs of climate change, i.e. the sum of mitigation costs and climate change damages. To reach this aim, the planner can either reduce fossil-fuel emissions or use carbon sequestration.

\subsection{Fossil-fuel emissions and abatement}

Let time be discretely indexed by $t(0 \leq t \leq T)$. Carbon dioxide emissions from combustion of fossil-fuels in the business as usual scenario are denoted $e_{t}$. At each period of time, the planner can decide to abate a quantity $a_{t}$ of these emissions, incurring costs $C_{t}\left(a_{t}\right)$. We assume $C_{t}$ to be twice differentiable convex functions, differing among time because of autonomous technical change. We also assume that $C_{t}(0)=0$, which means we do not consider potential "no regret" abatement potential. By construction, abatement $a_{t}$ is positive (1) and less than baseline emissions (2).

$$
\begin{aligned}
& 0 \leq \mathrm{a}_{\mathrm{t}} \\
& \mathrm{a}_{\mathrm{t}} \leq \mathrm{e}_{\mathrm{t}}
\end{aligned}
$$




\subsection{Land-use emissions and deforestation prevention}

Carbon sequestration aims at raising the amount of carbon sequestered in biomass and in soils with regard to the baseline. This encompasses a very wide range of activities, including establishment of timber plantations, encouragement of agroforestry and silvopastoral activities, improved farming practices, and prevention of deforestation (Watson et al., 2000). As announced in the introduction, we focus for the time being on the last item which may be cheap in some areas, potentially offers large cobenefits and is controversial on permanence grounds. Deforestation prevention also presents the advantage of limiting the analytical complexity of the model. We will come back to the general sequestration case in section 7.

Let us denote $f_{t}$ the reduction, relative to the baseline, in the area deforested during period $t$. By definition, this area is positive (3) and cannot exceed baseline deforestation for this period $d_{t}(4)$.

$$
\begin{aligned}
& f_{t} \geq 0 \\
& f_{t} \leq d_{t}
\end{aligned}
$$

For simplicity we assume a constant factor of proportionality $\eta$ (in tons of carbon per hectare) between $f_{t}$ and emissions reductions, though the actual factor will vary according to the biomass density of the forest and the land use that replaces it. Finally, we attribute all the avoided emissions to the period where the protection took place ${ }^{2}$.

We denote $\mathrm{CL}_{\mathrm{t}}$ the cost function of deforestation prevention at period $t$. This function represents payments compensating landowners for the foregone benefits of shifting to an alternative land-use ${ }^{3}$. We assume $\mathrm{CL}_{t}$ are convex and twice differentiable functions which pass through the origin.

\subsection{Carbon cycle and climate change damages}

Let us denote $\mathrm{el}_{\mathrm{t}}$ the baseline anthropogenic emissions from land-use ${ }^{4}$. Total anthropogenic emissions in the atmosphere $E_{t}$ are then given by (5) below, where $-\eta f_{t}$ refers to the reduction in emissions due to deforestation prevention with regard to the baseline $e^{5,6}$.

$$
E_{t}=e_{t}+e l_{t}-a_{t}-\eta f_{t}
$$

We use the simplified carbon cycle model designed by Nordhaus (1992). The model is represented in equation 6 below, where $\mathrm{M}_{t}$ denotes the atmospheric $\mathrm{CO}_{2}$ concentration over preindustrial equilibrium $M_{-\infty}$ and where $M_{0}$ is exogenously given. Parameter $\beta$ can be interpreted as the fraction of $\mathrm{CO}_{2}$ emissions

\footnotetext{
${ }^{2}$ If periods are at least one year long ( 5 years in our numerical simulations), we can consider this assumption to be roughly valid, in first order approximation. Bolin et al. (2000) indeed assume that, on average, carbon release is complete two years after deforestation. For deforestation in the Amazon, Houghton et al. (2000) estimate that $20 \%$ of biomass is burned, $70 \%$ is left as slash, $8 \%$ removed for products and $2 \%$ converted to elemental carbon through burning, with respective rate of decays of $0.1 \mathrm{yr}^{-1}, 0.1 \mathrm{yr}^{-1}$ and $0.001 \mathrm{yr}^{-1}$ for the last three. Assuming equal carbon contents, these figures imply that $28 \%$ of carbon is released one year after deforestation, $52 \%$ five years after and $71 \%$ ten years after.

Conceptually these payments finance not only plot-level opportunity costs but sectoral interventions such as agricultural intensification that ensure that there is no leakage.

${ }^{4}$ We do not impose any particular relationship between $\mathrm{el}_{\mathrm{t}}$ and $\mathrm{d}_{\mathrm{t}}$ as sequestration may be included in the baseline, and as the amount of deforestation the planner is able to avoid may be less important than the baseline deforestation for the considered year

${ }^{5}$ In this introductory section, we present the simplest case where deforestation prevention is permanent. Changes in equation (5) when deforestation prevention is temporary will be introduced in sections 4 and 5 .

${ }^{6}$ In this first model, we assume that once an hectare is cleared, no subsequent regrowth occurs.
} 
which is reabsorbed immediately within the ocean. The remainder is stocked in the atmospheric reservoir and slowly leaks back to sinks over time at rate $\delta$.

$$
M_{t+1}=M_{t}+\beta E_{t}-\delta M_{t}
$$

Nordhaus' carbon cycle model is easy to parameterize and to embed in an optimization model. But it underestimates both short term and long term concentrations (Joos et al., 1999) ${ }^{7}$. Nevertheless, we claim that our analytical results would still remain valid using more complex carbon cycle representations. We will indeed see that they depend primarily from the fact - accepted by climate scientists - that the flux of carbon from the atmosphere to the ocean is positively correlated with atmospheric $\mathrm{CO}_{2}$ concentration. This is reflected, though crudely, in Nordhaus' model through parameter $\delta$.

In order to limit the analytical complexity of our model, we assume that climate change damages in year $t$ depend on spot concentration $M_{t}$ through a twice differentiable function $D_{t}$ such that damages at current concentration are zero. This is a restrictive hypothesis: current damages may indeed depend not only on the spot, but on the whole path of atmospheric $\mathrm{CO}_{2}$ concentration. Mean surface temperature, for instance, depends on concentration history (Svirezhev et al., 1999). It can be demonstrated, however, that using temperature instead of concentration would not modify our qualitative results.

\subsection{Terminal condition and planner's objective function}

The choice of horizon $T$ plays a central role in the model's behavior, as damages beyond this point are not factored in the analysis. To minimize the effects of this choice, we make the following assumptions. First, we assume that, when concentration returns to current levels or below, damages are zero, and marginal damages are less than or equal to current marginal damages. Second, we assume that in the baseline, anthropogenic $\mathrm{CO}_{2}$ emissions return back to zero at some point in the future as the result of the diffusion of carbon-free technologies. According to the carbon-cycle (6), baseline concentration will therefore go back to current levels at some subsequent time ${ }^{8}$. Third, we choose for horizon $\mathrm{T}$ precisely that later date. By doing so, we ensure that, whatever the abatement path, concentration is below current level at horizon T: no damage beyond this date is considered.

If some carbon is stored through sequestration programs, however, it may still be released after horizon $\mathrm{T}$, hence resulting in concentration increase and further damages. We therefore assume that any ton of carbon sequestered up to period T-1 - the last period whose emissions count for concentration $\mathrm{M}_{\mathrm{T}}$ is in fact sequestered forever. The costs for $\mathrm{T}-1, \mathrm{CL}_{\mathrm{T}-1}\left(\mathrm{f}_{\mathrm{T}-1}\right)$, include the costs of permanent sequestration from this point onward.

The planner's objective function is then (7) below, in which $\theta$ is the annual discount factor'.

$$
\operatorname{Min}_{\left(a_{t}, f_{t}\right)} \sum_{t=0}^{T}\left[C_{t}\left(a_{t}\right)+C L_{t}\left(f_{t}\right)+D_{t}\left(M_{t}\right)\right] \theta^{t}
$$

\footnotetext{
${ }^{7}$ Joos et al. identify two main shortcomings of the model. First, the instantaneous reabsorption of a fraction $\beta$ of emissions is in fact much slower. Second, all the $\mathrm{CO}_{2}$ emitted "in excess" since the industrial revolution will not be absorbed in the ocean: the law of chemistry indeed states it should be split between atmospheric and oceanic reservoirs. Ultimately however, its sequestration in soils and in the deep layers of the ocean will lead to a complete removal, but on a much longer time horizon than Nordhaus' model indicates (Kattenberg et al., 1996).

${ }^{8}$ The fact that our carbon cycle underestimates carbon resilience in the atmosphere implies that this time is not too faraway in the future.

${ }^{9}$ If $\rho$ is the annual discount rate, then $\theta=\frac{1}{1+\rho}$.
} 


\section{Permanent sequestration: equivalent to energy abatement, as long as past decisions do not impact on present costs}

In this section, we assume the planner is able to secure contracts guaranteeing that the land will remain forested until horizon $\mathrm{T}$. With an up-front payment, the planner therefore compensates landowners for the whole stream of foregone revenues from period $t$ to period $T$ and at the same time avoids leakage by intensifying agriculture, ranching or silviculture somewhere else from period $t$ to period $T$. At each period of time, we assume that because of the heterogeneity in costs of protection there is a supply curve for averted deforestation $\mathrm{CL}_{t}\left(\mathrm{f}_{\mathrm{t}}\right)$. This represents the minimum possible cost of reducing the current flow of deforestation during period $t$ by $f_{t}$ hectares relative to the baseline.

We must then distinguish two cases depending on whether these costs depend only on current prevention $f_{t}$ or also on past decisions $f_{t-1}, f_{t-2}, \ldots, f_{0}$. For the first hypothesis to be valid, both compensations to landowners and agriculture intensification must be independent from period to period. For example, opportunities to prevent deforestation might arise in different regions at each period of time. An expanding frontier of low-productivity semi-subsistence farming might be another example. As the frontier passes, forest land is converted to slash and burn agriculture, then abandoned to incomplete regrowth. In this model, each period presents an independent new supply curve for deforestation prevention.

On the other hand, global land scarcity may induce $\mathrm{CL}_{\mathrm{t}}$ functions to depend on both present and past protection decisions. This might also result from intensification programs where the costs of an unit of productivity gain rise with the quantity of gains already realized. In section 3.1, we start with the assumption that each $\mathrm{CL}_{t} \mathrm{O}$ is a function only of current deforestation prevention $\mathrm{f}_{\mathrm{t}}$. In section 3.2 we will examine the case of increasing costs for preventing deforestation as a function of cumulative past protection ${ }^{10}$.

In both cases, sequestration is permanent, so carbon is never released. Equation (5) remains unchanged.

\subsection{When past decisions do not matter, marginal abatement and sequestration costs are equalized}

Detailed derivation of first order conditions for model (1)-(7) are provided in Annex 1. The key result is that, along the optimal path, as long as maximum abatement is not required (constraint 2 not binding), and as long as the supply of "protectable" forest is not exhausted (constraint 4 not binding), the marginal costs of abating and sequestering carbon should be equal (8).

$$
C L_{t}^{\prime}\left(f_{t}\right)=\eta C_{t}^{\prime}\left(a_{t}\right)
$$

In this case, sequestration and abatement are perfect substitutes from a climate point of view.

\subsection{When past decisions matter, a slightly more complex equilibrium}

Let us now assume that sequestration costs depend on both the incremental surface put under protection $f_{t}$ and the total protected areas $F_{t-1}=f_{0}+f_{1}+\ldots+f_{t-1}$, with partial derivative of $C L_{t}$ with regard to $f$ and $F$ positive. Again, marginal abatement costs are equal to marginal sequestration costs. But in this case, setting one additional hectare under protection entails costs not only at present period (first term in

\footnotetext{
${ }^{10}$ The same might actually be true in the energy sector.
} 
the right-hand side of equation 9 below), but also at each subsequent periods (second term). As a result, the marginal sequestration cost $-\partial \mathrm{CL}_{\mathrm{t}} \partial \mathrm{f}_{\mathrm{t}}$ - is now less than marginal abatement costs.

$$
\eta \cdot C_{\mathrm{t}}^{\prime}\left(\mathrm{a}_{\mathrm{t}}\right)=\frac{\partial C L_{\mathrm{q}}}{\partial \mathrm{f}}\left(\mathrm{f}_{\mathrm{q}}, \mathrm{F}_{\mathrm{q}-1}\right)+\sum_{\mathrm{q}=\mathrm{t}+1}^{\mathrm{T}} \frac{\partial \mathrm{CL}_{\mathrm{q}}}{\partial \mathrm{F}}\left(\mathrm{f}_{\mathrm{q}}, \mathrm{F}_{\mathrm{q}-1}\right) \theta^{\mathrm{q}}
$$

Does it mean more or less sequestration? If we assume that, at each period, the marginal sequestration costs remain the same (that is the partial derivatives of $\mathrm{CL}_{t}$ with regard to $\mathrm{f}_{t}$ ) as in the preceding model, then sequestration becomes overall more expensive when history is taken into account. As a result, (i) the balance between abatement and sequestration shifts towards abatement, and (ii) as action overall becomes more expensive, the global damage/cost equilibrium shifts towards less emission reduction. Both effects tend to reduce the surface of forest which is put under protection.

\section{Temporary sequestration: where marginal damages play a critical role}

Let us turn to temporary sequestration. We now assume that sequestration projects are not permanent, but defer emissions for exactly $\tau$ years. Anthropogenic emissions are now given by equations (10) and (11) below, which replace (5) in previous model to take carbon release at the end of each sequestration project into account. All the other equations remain unchanged, except that sequestration costs $\mathrm{CL}_{t}\left(\mathbf{f}_{t}\right)-$ for simplicity's sake, we assume that the total surface of forest put under protection does not impact on protection prices - now represent the costs of preventing deforestation for a fixed period of $\tau$ years.

$$
\begin{array}{ll}
E_{t}=e_{t}+e l_{t}-a_{t}-\eta f_{t} & \text { for } 0 \leq t \leq \tau-1 \\
E_{t}=e_{t}+e l_{t}-a_{t}-\eta f_{t}+\eta f_{t-\tau} & \text { for } \tau \leq t \leq T
\end{array}
$$

Derivation of first order conditions for model $(1,2,3,4,6,7,10,11)$ is given in annex 2 . To facilitate the exposition of the results, let us introduce the spot shadow price of atmospheric carbon that we denote $\lambda_{t}$. Along the optimal path, $\lambda_{t}$ is equal to the discounted sum of the flow of incremental damages the release of one additional unit of carbon in the atmosphere would cause.

Along the optimal path, it is therefore not surprising that marginal abatement costs are equal to the shadow price of atmospheric carbon, at least as long as some abatement is necessary (constraint 1 not binding) or all the abatement opportunities are not exhausted (constraint 2 not binding) ${ }^{11}$.

$$
C_{t}^{\prime}\left(a_{t}\right)=\lambda_{t} \beta
$$

The same is not true, however, for temporary sequestration. Such projects indeed simply postpone emissions by $\tau$ periods, and therefore offset only part of the stream of climate change damages caused by the emission of one additional ton of carbon. A given temporary sequestration project will be undertaken only if the shadow price of carbon - and therefore the cost of abatement - is lower in discounted terms at period $t+\tau$ than it is at period $t$. And the optimum is reached when, at each period of time, the planner is indifferent between abating one unit of fossil-fuel emissions now or bundling together a $\tau$-period sequestration project starting now and a fossil-fuel emission reduction project in $\tau$ periods ${ }^{12}$.

$$
\mathrm{CL}_{t}^{\prime}\left(\mathrm{f}_{\mathrm{t}}\right)=\left(\lambda_{\mathrm{t}}-\lambda_{\mathrm{t}+\tau} \theta^{\tau}\right) \eta \beta \quad \text { for } \mathrm{t} \leq \mathrm{T}-\tau
$$

\footnotetext{
${ }^{11}$ Factor $\beta$ in equation (12) accounts for the fact that only a fraction $\beta$ of emissions is not immediately reabsorbed in Nordhaus' carbon cycle model.

${ }^{12}$ Equation (13) is of course valid as long as constraints (3) and (4) are not binding. The additional $\eta$ multiplier translates shadow prices (in $\$$ per tons of carbon) in deforestation prevention costs (in $\$$ per hectare).
} 
This rule has two interesting consequences:

- First, if the shadow price of atmospheric carbon rises at a rate higher than the rate of discount between periods $t$ and $t+\tau$, then no temporary sequestration project starting from period $t$ is costeffective.

- Second, even if the price of atmospheric carbon rises at a rate lower than the rate of discount, temporary sequestration is cost-effective if and only if its costs are lower than the atmospheric carbon price difference.

The key issue for temporary sequestration is therefore to understand the trajectory of the implicit price of atmospheric carbon along the optimal path. We make this detour in sub-section 4.1, then conclude our analysis of the optimal use of temporary sequestration in 4.2 and discuss optimal value for $\tau$ in 4.3 .

\subsection{High or low marginal damages? Two paths for the shadow price of carbon}

Rigorous computation of the optimal dynamics of the shadow price of atmospheric carbon $\lambda_{t}$ is given in annex 1 . We propose here an intuitive derivation of the result.

Let us reason backward. At penultimate period T-1, the costs associated with one additional unit of carbon in the atmosphere are only the incremental damages triggered by this unit at period $\mathrm{T}$ (as $\mathrm{T}$ is the horizon of the analysis). The shadow value of carbon at period T-1 is therefore given by:

$$
\lambda_{\mathrm{T}-1}=\theta \mathrm{D}_{\mathrm{T}}^{\prime}\left(\mathrm{M}_{\mathrm{T}}\right)
$$

Given the choice of horizon $\mathrm{T}$, we know that concentration at horizon $\mathrm{T} \mathrm{M}_{\mathrm{T}}$ is less than or equal to current concentration, and that marginal damages of climate change are less than or equal to current marginal damages.

Let us now go one period backward. The release of one more unit of carbon in the atmosphere in period T-2 will trigger damages at period T-1, and damages at period T. However, because of the "leak" term $\delta$ in the carbon cycle model, releasing one more unit of carbon in the atmosphere at period T-2 actually triggers less incremental damages at period $\mathrm{T}$ than releasing the same amount at period $\mathrm{T}-1$. A fraction $(1-\delta)$ of this carbon has been reabsorbed by the oceans or the soil. The shadow price of carbon at period $\mathrm{T}-2$ is therefore given by:

$$
\lambda_{\mathrm{T}-2}=\theta \mathrm{D}_{\mathrm{T}-1}^{\prime}\left(\mathrm{M}_{\mathrm{T}-1}\right)+(1-\delta) \theta^{2} \mathrm{D}_{\mathrm{T}}\left(\mathrm{M}_{\mathrm{T}}\right)=\theta \mathrm{D}_{\mathrm{T}-1}^{\prime}\left(\mathrm{M}_{\mathrm{T}-1}\right)+(1-\delta) \theta \lambda_{\mathrm{T}-1}
$$

This reasoning can be repeated, to yield the general form of the shadow price of carbon along the optimal path:

$$
\lambda_{t}=\sum_{q=t+1}^{T} \theta^{q-t}(1-\delta)^{q-t-1} D_{q}^{\prime}\left(M_{q}\right)
$$

It will in fact prove easier to use the backward induction equation:

$$
\lambda_{\mathrm{t}-1}=(1-\delta) \theta \lambda_{\mathrm{t}}+\theta \mathrm{D}^{\prime}\left(\mathrm{M}_{\mathrm{t}}\right) \quad \text { for } 1 \leq \mathrm{t} \leq \mathrm{T}-1
$$

What does (17) imply for the evolution of $\lambda_{t}$ along the optimal path? First, as the discounted shadow price of carbon is less at period $T$ than it was at initial period ${ }^{13}(14)$, we know that $\lambda_{t}$ will ultimately decrease. But for the first periods, equation (17) simply states that $\lambda_{t}$ can cannot rise at a rate higher than the rate of discount plus $\delta$, the rate of "depreciation" of atmospheric carbon. Consequently, the discounted

\footnotetext{
${ }^{13}$ Indeed, we have $\lambda_{T-1}=\theta D_{T}^{\prime}\left(M_{T}\right)$. By construction of $T$, we guarantee that $M_{T} \leq M_{0}$ and $D_{T}^{\prime}\left(M_{T}\right) \leq D_{0}^{\prime}\left(M_{0}\right)$. At the same time, we know from equation (17) that $\lambda_{0}>\theta \mathrm{D}_{1}^{\prime}\left(\mathrm{M}_{1}\right) \geq \theta \mathrm{D}_{0}^{\prime}\left(\mathrm{M}_{0}\right)$. Thus $\lambda_{\mathrm{T}-1}<\lambda_{0}$ and $\lambda_{\mathrm{T}-1} \theta^{\mathrm{T}-1}<\lambda_{0}$.
} 
price of atmospheric carbon can follow either one of the different paths illustrated below: rise and decrease, with possibly several oscillations before finally decreasing (Figure 1), or decrease from the start (Figure 2).

Which path we follow depends on two elements: the marginal damages of climate change, especially at low concentration levels, which drives the variations of $\lambda_{t}$ in equation (17), and the global equilibrium between climate change damages, abatement costs and baseline emissions, which drives the value of $\lambda_{0}$. We will see numerically that the first path appears to be more plausible than the second (section 6). At this analytical level, however, all we can say is that if marginal climate change damages are zero at low concentration levels, we are in the first scenario regardless of the initial value of $\lambda_{0}$.

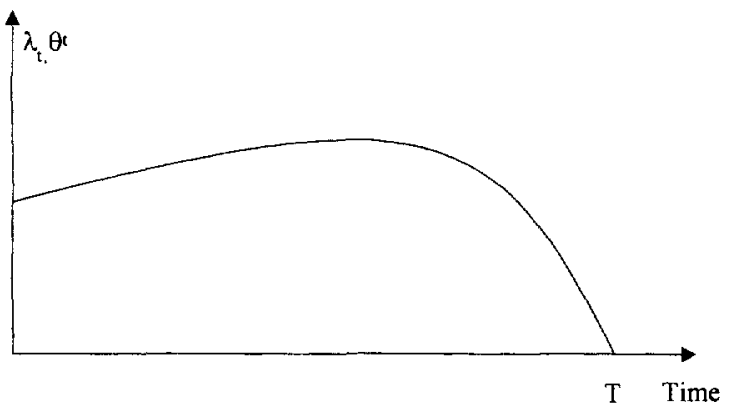

Figure 1: Optimal discounted price of atmospheric carbon with low marginal abatement costs at low concentration levels.

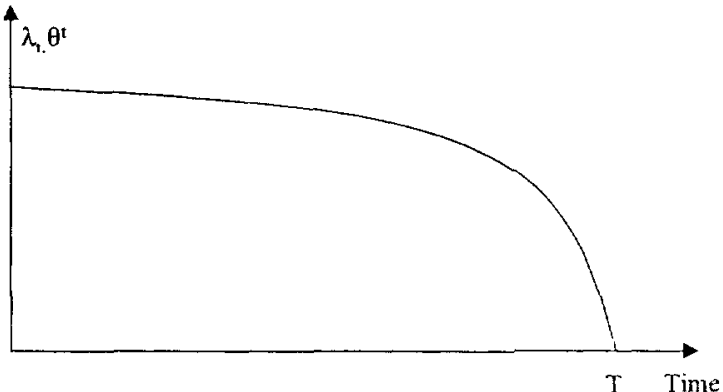

Figure 2: Optimal discounted price of atmospheric carbon with high marginal abatement costs at low concentration levels.

\subsection{Temporary sequestration is cost-effective only when current marginal damages are high enough}

We can now come back to rule (13) and examine under which conditions temporary sequestration occurs. If the shadow price of carbon rises at a rate higher than the rate of discount between periods $t$ and $\mathrm{t}+\tau$, then it is not cost-effective to undertake any $\tau$-period sequestration projects. They would indeed bridge the gap to a period where, along the optimal path, the marginal abatement cost is in fact higher (even in discounted terms) than it is at period $t$. The preceding discussion informs us that such a situation occurs when marginal damages at low concentration levels are low or nil.

On the contrary, if the shadow price of carbon rises at a rate lower than the rate of discount between periods $t$ and $t+\tau$, then some of the temporary sequestration projects are undertaken up to the point where the costs of sequestration just bridge the difference (in discounted terms again) between present and future shadow prices of carbon. When this difference becomes too large, all the available deforestation prevention projects are undertaken (that is $\mathrm{f}_{\mathrm{t}}=\mathrm{d}_{\mathrm{t}}$ ).

We have seen that the shadow price of atmospheric carbon will eventually decrease along an optimal path. We are therefore sure that, beyond some point in the future, the shadow price of carbon will rise at a rate lower than the rate of discount, and therefore that, beyond this point, some $\tau$-period long temporary sequestration will become cost-effective. However, depending on the shape of the damage function and on the emission baseline, this point might come at the very first period or on the very far in the future. 


\subsection{On the optimal length of deforestation prevention}

In the above analysis, the length of temporary deforestation prevention $\tau$ was fixed. Let us now discuss the optimal value of this parameter. To this aim, let us consider a $\tau$-period temporary sequestration project worthwhile undertaking along the optimal climate mitigation path. This means that the cost of this project are more than offset by the benefits in terms of discounted shadow prices of carbon. We denote $\Delta$ the difference.

Does it make sense to extend protection by one additional period? The project obviously becomes more expensive. But on the other hand, the difference of discounted shadow prices of carbon between present period and termination periods also grows. The key issue is therefore to know whether the net gain $\Delta$ plus this incremental difference still remains positive. Two cases are therefore possible:

- If the costs of extending protection become high enough not only to offset further gains in terms of shadow price of carbon, but also to offset the initial benefit of the project $(\Delta)$, then it becomes useless to further extend protection. This equilibrium is defined precisely as the point where the planner is indifferent between abating now, or bundling sequestration and future abatement.

- On the other hand, extending protection might even add to $\Delta$ (if, for instance, beyond some threshold, extending deforestation prevention further becomes nearly cost-free). In this case, the optimal length of the project is in fact until horizon $\mathrm{T}$, that is permanent sequestration.

We now go one step further and assume the planner can choose the length of forest protection, in a model where the quantity of forest already put under protection matters.

\section{Optimal deforestation prevention for carbon sequestration}

\subsection{Deforestation prevention for a single body of forest: the model}

In the two previous sections, only one type of sequestration, either temporary or permanent, was admissible at the same time. We now combine both options. We assume a unique forest which shrinks by an incremental $d_{t}$ hectares at each period in the baseline scenario. At each period, however, the planner can compensate potential deforesters and save $f_{t}$ hectares out of the $d_{t}$, adding to a total "belt" of $F_{t}$ hectares (equation 18) around what would have remained standing at period $t$ in the baseline. To account for the possibility of temporary sequestration, the incremental area protected at one given time may be negative, which implies that constraint (3) is replaced by (19) below.

$$
F_{t}=\sum_{q=0}^{t} f_{q}
$$

$F_{t} \geq 0$

We model deforestation as follows. At period $t$, given the structure of the transportation system and the general demand for agricultural land, we assume an implicit revenue from agriculture or ranching can be associated with each point of land. If, at the beginning of a given period, this implicit revenue is positive for some forested patch of land, this surface will be deforested during this period so that, at the end of the period, the deforestation frontier reaches the point where the implicit revenue from agriculture is zero. From one period to the next, however, rising demand for agricultural land as well as improvements in the transportation network shifts this function upward, triggering further deforestation. 
The planner's sequestration policy is a combination of compensations to "would be deforesters" and of measures aimed at intensifying agriculture and ranching elsewhere in the country. However, given the above model of deforestation, we assume that at each period of time the hectares the planner is able to protect from deforestation are the ones which are closest to the baseline frontier, where distance from markets and roads make agriculture or ranching the least attractive. This policy thus "holds back" deforestation frontier from where it would be otherwise ${ }^{14}$ (see Figures $3 a, b$ and $c$ ).

Contrary to the preceding two cases, however, where the planner could secure long term contracts, we assume here he cannot prevent deforestation from more than one period at a time. If he stops paying at one point of time, a rapid clearing of the total protected area $F_{t}$ thus occurs. In other words, the policies he puts in place have to be renewed at each period, and do not have long term effects. Under these assumptions, costs $\mathrm{CL}_{t}$ now depend on the total area protected $F_{t}$ and not on the incremental $f_{t}$.

The objective function therefore becomes:

$$
\operatorname{Min}\left(a_{t}, f_{t}\right) \sum_{t=0}^{T}\left[C_{t}\left(a_{t}\right)+C L_{t}\left(F_{t}\right)+D_{t}\left(M_{t}\right)\right] \theta^{t}
$$

\subsection{Two patterns of deforestation prevention}

Derivation of first order conditions for problem $(1,2,3,5,6,18,19,20)$ is presented in annex 3 . The key result is that optimal sequestration may follow two different optimal paths depending on the marginal climate change damages at low concentration levels.

- When marginal damages are high, sequestration starts at the first period and temporary sequestration between consecutive periods is possible

- When marginal damages are low at low concentration levels, sequestration follows a "bang-bang" path: no protection at first, and then full protection of all remaining forest (and temporary sequestration between consecutive periods is not possible during first periods)

\section{When marginal damages are high, sequestration starts at the first period and temporary sequestration between consecutive periods is possible}

We know from the above discussion that, when marginal damages are sufficiently high, the shadow price of carbon rises at a rate lower than the discount rate from the very first period onward (the dynamics of shadow price $\lambda_{t}$ are indeed the same in this model as they were in the two previous sections). At each period, the planner has an interest in making at least some temporary deforestation, which thus begins from the start.

What is the optimal deforestation prevention path? Using the same reasoning as in section 4.3 , we see that forest should be protected between the first and second periods up to the point where marginal costs of one period protection exactly compensate the diminution of discounted shadow price of carbon during this interval. Hence the value of $f_{0}$ (and therefore of $F_{0}$ ). The same reasoning can be applied at each period, hence yielding the successive values of $F_{t}$ through equation (21) below.

$$
\mathrm{CL}_{\mathrm{t}}^{\prime}\left(\mathrm{F}_{\mathrm{t}}\right)=\left(\lambda_{\mathrm{t}}-\lambda_{\mathrm{t}+1} \theta\right) \eta \beta \quad \text { for } 0 \leq \mathrm{t} \leq \mathrm{T}-1
$$

\footnotetext{
${ }^{14}$ It is important to note that there is no guarantee that individual plots will be preserved. Indeed, even if one hectare is protected at first period, rising revenue from agriculture at this spot make it more interesting to let it cut down at second period to protect another hectare further out on the frontier.
} 


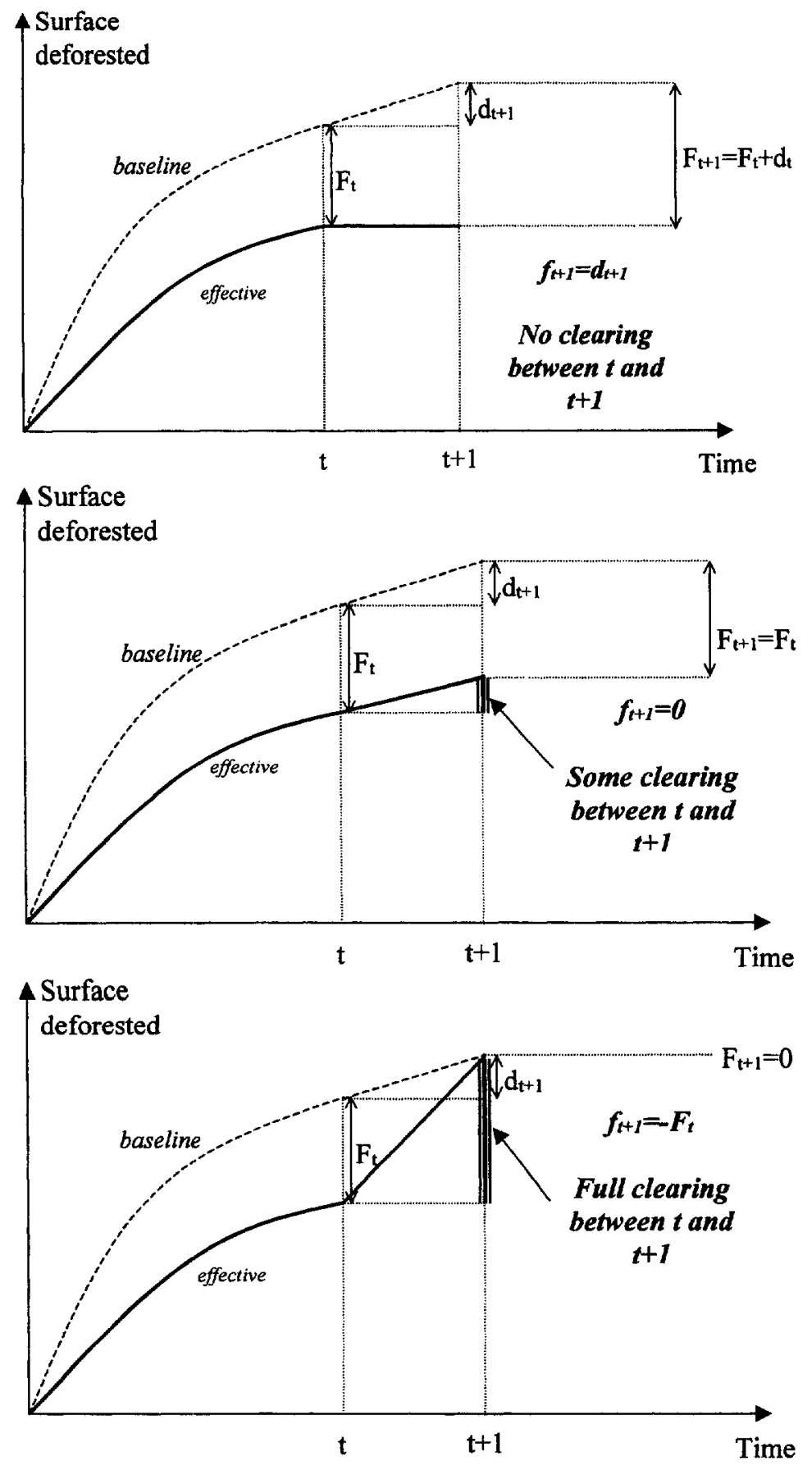

Figures $3 a, b$ and $c$ : Three possible decisions regarding deforestation at period $t+1$. First, the planner extends the area already protected $(F$, by an amount equivalent to the area which should be deforested under the baseline $\left(d_{1+1}\right)$. The forest frontier remains unchanged, and there is no release of carbon between periods $t$ and $t+1(3 a)$. In $3 b$, the planner simply keeps the total amount of forest under protection constant $\left(f_{t+1}=0\right)$. There are emissions as the planner swaps areas previously protected, but too expensive to keep protected now, with areas closer to the baseline frontier. $3 c$ is the extreme case where the planner abandons all protection $\left(f_{t+1}=-F_{1}\right):$ the whole surface under protection at period $t\left(F_{1}\right)$ plus the area which had to be cleared in the baseline $\left(d_{i+1}\right)$ are cleared. 
In other words, at each point of time, the marginal cost of permanent sequestration equals the shadow price of carbon (the shadow price of carbon at this period is by definition zero at last period). These properties are valid as long as both sequestration and abatement supplies are not exhausted (i.e. as long as constraints 2 and 4 remain not binding).

$$
\sum_{q=t}^{T} C L_{q}^{\prime}\left(F_{q}\right) \theta^{q-t}=\lambda_{t} \eta \beta \quad \text { for } 0 \leq t \leq T-1
$$

When marginal damages are low at low concentration levels, sequestration follows a "bang-bang" path: no protection at first, and then full protection of all remaining forest (and temporary sequestration between consecutive periods is not possible during first periods)

When marginal damages are low at low concentration levels, we have seen that the price of atmospheric carbon rises at a rate higher than the rate of discount during the first periods (equation 13). Consequently, deforestation prevention projects which start and end within this time interval are unattractive. They would postpone emissions to a point where the discounted shadow price of carbon is higher than it was at the start of the project. As a result, $F_{0}, F_{1}$, and all subsequent $F_{t}$ in the time interval during which the discounted shadow price of carbon is above its initial value should be zero (i).

But on the other hand, we know that the discounted shadow price of carbon will eventually become lower than it was at period 0 . Consequently, some deforestation prevention projects starting during the first periods, but ending beyond this time interval are cost-effective. As a result, some of the $\mathrm{F}_{0}, \mathrm{~F}_{1}$, and subsequent $F_{t}$ in the time interval during which the discounted shadow price of carbon is above its initial value should be strictly positive (ii).

There is an obvious contradiction between (i) and (ii). The reason for that is that, along any sequestration path $\left(F_{t}\right)$, and henceforth along the optimal one $\left(F_{t}^{*}\right)$, the discounted marginal cost of preventing the emission of one more ton of carbon till horizon $\mathrm{T}$ is by construction decreasing with time. On the other hand, the discounted shadow price of carbon is rising during the first periods. Contrary to the preceding case (equation 22), there is therefore no way both quantities can be equated at all points in time.

As a result, the optimal use of sequestration is a "bang-bang" solution. Before a "turning point", there is no sequestration at all $\left(f_{t}=0\right)$, and after this point, all the remaining forest standing is protected (that is $f_{t}=d_{t}$ ) (see annex 3 for a rigorous derivation of this result). The marginal cost of permanent sequestration along the optimal path is higher than the discounted shadow price of carbon before the "turning point" and lower afterwards. Only at the "turning point" period itself do we observe an equalization of both quantities in the model of equation (22).

To examine which path is actually chosen, and disentangle the role of the different parameters, we now turn on to numerical simulations of the above model. 


\section{Numerical simulations}

To gain insights on how the shape of climate change damages affects the cost-effectiveness of sequestration, especially during the first periods of the simulation which are the most relevant for decision-making, we make numerical simulations of the model of deforestation prevention developed in the last section using the GAMs software.

\subsection{Model calibration}

\section{Fossil-fuel baseline emissions and abatement costs}

We assume business-as usual world fossil-fuel emissions grow at the rates of the IPCC IS92a scenario between 2000 and 2100 (Leggett et al., 1992, figures from Morita and Lee, 1997) with 2000 figures updated using latest IEA data (2000). Beyond 2100, emissions are assumed to decrease linearly and stop completely in 2200 . With this anthropogenic forcing, carbon cycle (6) predicts atmospheric carbon dioxide concentration would eventually decrease back to current level in the last quarter of the 24th century. We therefore set our time horizon $\mathrm{T}$ in 2400 , dividing time in 5-year periods between 2000 and 2200 , and in 25-year periods afterwards.

World marginal abatement costs are assumed to be zero at the origin - we do not take "no regret" potential into account - and to rise quadratically with abatement. The function is parameterized assuming a carbon free backstop technology initially available at $\$ 900$ per ton of carbon. We assume autonomous technical change cuts this price by half every 50 years (that is by $1.38 \%$ annually).

The discount rate is set at $5 \%$.

\section{Land-use $\mathrm{CO}_{2}$ emissions and sequestration costs}

Anthropogenic land-use $\mathrm{CO}_{2}$ emissions derive essentially from tropical deforestation. IPCC estimates this flux at an average $1.7 \pm 0.8 \mathrm{GtC} . \mathrm{yr}^{-1}$ between 1980 and 1989 , and $1.6 \pm 0.8 \mathrm{GtC}^{-y^{-1}}$ between 1990 and 1999 (Bolin et al., 2000), with global deforestation rates estimated 15.1 Mha.yr ${ }^{-1}$ between 1970 and 1990 (Dixon et al., 1994). Most models forecast from very limited deforestation to fairly important forest regrowth starting beyond 2050 as world population tends to stabilization, agriculture becomes more productive, and economic growth provides better job opportunities in the secondary or tertiary sectors. But the short and medium term transition is much more controversial: some models indeed project a smooth decline of deforestation over this period, while other forecast a sharp rise followed by a steep decrease (see Nakićenović et al., 2000). Recent FAO data for the 1990-2000 decade see, to point towards smooth decline (FAO, 2000b). In our baseline scenario, we will assume a median trend of a constant deforestation rate of $8 \mathrm{Mha}_{\mathrm{yr}} \mathrm{-}^{-1}$ over the next five decades, followed by no deforestation at all beyond this point.

The quantity of carbon released through deforestation in the tropics depends on the subsequent landuse. Dixon et al. (1994) assume deforestation prevention saves, on average, $181 \mathrm{tC}$.ha ${ }^{-1}$. Sampson et al. (2000) find cropping after slash and burn of tropical forest release between 152 tC.ha $^{-1}$ and 224 tC.ha $^{-1}$ (with a mean value of $184 \mathrm{tC} \cdot \mathrm{ha}^{-1}$ ). We choose here $\eta=200 \mathrm{tC} \cdot \mathrm{ha}^{-1}$, which, combined with our land-use scenario, leads to land-use $\mathrm{CO}_{2}$ emissions of $1.6 \mathrm{GtC}_{\mathrm{yr}}{ }^{-1}$ over the $2000-2050$ period.

To model deforestation prevention policies, we assume that at each period, households clear land to establish pasture and cropping up to the point where the revenue they can expect from these activities (all 
costs included) drops to zero. In our baseline land-use scenario, exogenous drivers such as total demand for food cause the zero expected revenue line further and further away in the forest, thus triggering steady deforestation over the 2000-2050 period. However, we assume that the international community can divert some of these households from deforesting by a combination of compensations to households and complementary measures (for instance agriculture intensification) to avoid leakage..

Assuming that the least suitable land for agriculture are protected first at each point of time, the foregone revenue per hectare is assumed to be increasing with the amount of forest put under protection with regard to the baseline. At each point of time, the maximum total area that can be put under protection is obviously the total area that would have been deforested in the baseline between 2000 and the end of the considered period. We will, however, assume that only half of total world deforestation $-4 \mathrm{MtC}_{\mathrm{yr}}{ }^{-1}-$ can be addressed through carbon-related policies. We choose quadratic $\mathrm{CL}_{\mathrm{t}}$ functions, with $\mathrm{CL}_{\mathrm{t}}(0)=0$ (costs when no forest is protected are zero), $\mathrm{CL}_{\mathrm{t}}^{\prime}(0)=0$ (marginal cost of first hectare protected is zero) and $\mathrm{CL}_{\mathrm{t}}\left(\sum_{\mathrm{q}=0}^{\mathrm{t}} \mathrm{d}_{\mathrm{q}}\right)$, i.e., the marginal annual cost of full protection, starts at $\$ 100 / \mathrm{ha}$, rising at a $3 \%$ rate until 2050 and stabilizing afterwards.

\section{Carbon cycle and climate change damages}

We calibrate the carbon cycle using values from Nordhaus (1992): $\beta=0.38, \delta=0.082$, preindustrial $\mathrm{CO}_{2}$ concentration of $274 \mathrm{ppm}$. We estimate 2000 atmospheric $\mathrm{CO}_{2}$ concentration at $370 \mathrm{ppm}$ on the basis of Keeling and Whorf (2000).

It has been pointed out that widely used "smooth" damage functions - usually polynomial of degree 1 to 3 (Tol and Fankhauser, 1998) - do not correctly capture the possibility of catastrophic damages which could stem out either of highly non linear climate dynamics, such as a slowdown of the thermohaline circulation (Broecker, 1997), increased frequency of El Niño events, or of highly non linear responses to smooth climate change, such as sudden migratory pressure when agricultural supply reaches a threshold in the subtropics (Parry et al., 1999) or rapid changes in the opinion's concerns about the importance of the issue such as in the "mad cow" crisis in Europe (Streets and Glantz, 2000). To take these possibilities into account, threshold-type damage functions have also been proposed.

In the following simulations, we therefore use both aggregated damage function:

- polynomial damage function, where damages are zero at current concentration and rise linearly (we will also test quadratic and cubic functions) with concentration. As a benchmark figure, we assume that double preindustrial concentration level in 2100 would lead to a loss of $1 \%$ of world gross product damage at that time (that is 250 trillion dollars under scenario IS92a economic growth assumption).

- Threshold damage functions, where damages are assumed to be zero until a given ceiling is reached, and then rise sharply. For simplicity's sake, and to make the link with the cost-efficiency approach, we assume damages rise to infinity when the concentrations exceed the threshold. We first consider the $550 \mathrm{ppm}$ target, but we will also examine the $450 \mathrm{ppm}$ alternative. 


\subsection{Numerical insights}

\section{Threshold damage functions}

With threshold damage functions, marginal damages are assumed to be zero when concentration is lower than the threshold. In this case, we find the expected "bang-bang" behavior of sequestration use: no forest is protected at first, and then, beyond some "turning point", all remaining standing forest is protected. In our central scenario, the "turning point" is relatively distant in the future (2040) and the surface of forest preserved permanently is only 39 Mha out of the 200 that could have been protected in total $(19 \%)$. Strictly speaking, this is actually not permanent sequestration: these 39 Mha area are in fact deforested before horizon $T$ when the discounted shadow price of carbon ultimately decreases. But this happens so late, typically beyond 2160 , that for all practical purposes we can consider sequestration starting from the "turning point" to be permanent.

In Table 1 below, we explore several alternative scenarios to test the sensitivity of the "turning point" to the different assumptions of the model. First, the position of the threshold appears to have a strong impact on the "turning point". Forest protection starts in 2025 when the threshold is $500 \mathrm{ppm}$, and in 2005 when it is set at $450 \mathrm{ppm}$. These results stem from the fact that the lower the threshold is, the higher abatement costs need to be, and thus the (relatively) cheaper sequestration becomes.

In comparison, abatement costs in the fossil-fuel sector and discount rate appear to have less impact. First, even in a highly technology-optimistic scenario - double speed of autonomous technical change the "turning point" is just postponed by 5 years (scenario b). Second, lowering the discount rate to $3 \%$, which means the implicit "pure time preference" of the planner is close to zero, only brings the "turning point" closer by 5 years.

Similarly, even very optimistic assumptions about future deforestation prevention costs have a limited impact on the "turning point" and thus on the amount of forest which is ultimately protected. In scenario c, we indeed assume deforestation prevention becomes nearly free after 2050 ( $\$ 10$ per hectare and per year at most). As a result, the turning point comes back from 2040 to 2030 and the surface under protection doubles.

\begin{tabular}{ccccc}
\hline Threshold & discount rate & $\begin{array}{c}\text { Abatement and } \\
\text { sequestration } \\
\text { costs }\end{array}$ & Turning point & $\begin{array}{c}\text { Surface } \\
\text { protected from } \\
\text { deforestation }\end{array}$ \\
\hline 550 & $5 \%$ & a & 2040 & $39 \mathrm{Mha}$ \\
500 & $5 \%$ & a & 2025 & $89 \mathrm{Mha}$ \\
450 & $5 \%$ & $\mathrm{a}$ & 2005 & $170 \mathrm{Mha}$ \\
550 & $3 \%$ & $\mathrm{a}$ & 2035 & $41 \mathrm{Mha}$ \\
550 & $5 \%$ & $\mathrm{~b}$ & 2045 & $19 \mathrm{Mha}$ \\
550 & $5 \%$ & $\mathrm{c}$ & 2030 & $66 \mathrm{Mha}$ \\
\hline
\end{tabular}

Table1: Date at which deforestation prevention begins and surface ultimately protected from deforestation with threshold damages. a: abatement and sequestration costs assumptions made in the text, b: backstop technology price divided by four in 50 years instead of two; $c$ : sequestration virtually free beyond $2050(\$ 10 / \mathrm{ha} / \mathrm{yr})$.

We have demonstrated that at the root of this "bang-bang" dynamics is the fact that discounted marginal abatement costs and discounted marginal costs of permanent sequestration cannot be equalized over more than one period. We verify this property numerically. Figure 4 shows the discounted shadow price of carbon (continuous line) and the discounted marginal costs of permanent sequestration (black squares). We see that the former increases with time (at rate $\delta$ ) over the 2000-2060 period while the latter, 
decreases. Before 2040 ("turning point"), sequestration costs more at the margin, and there is no sequestration at all. But after 2040, the reverse becomes true, and all the remaining land is protected.

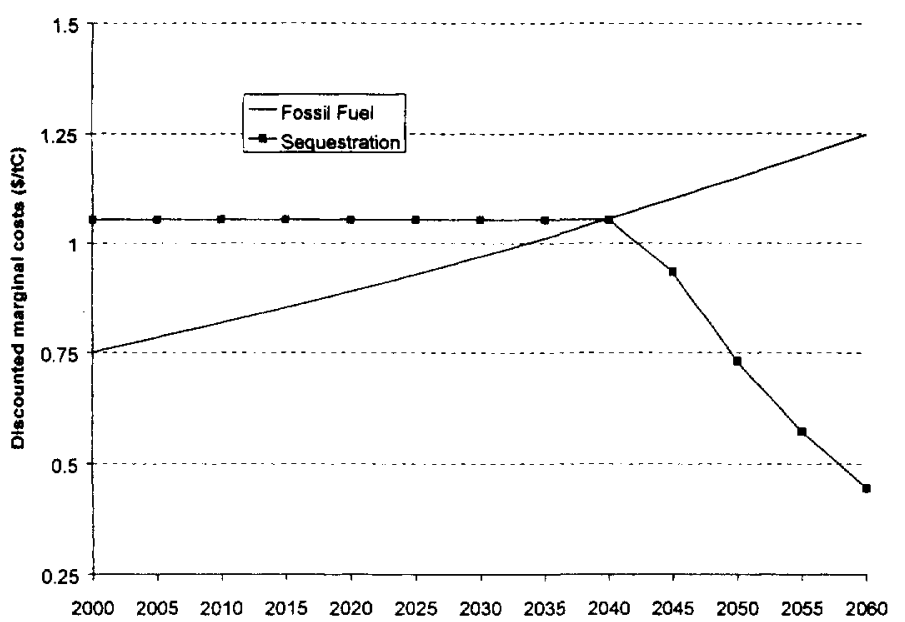

Figure 4: Discounted marginal fossil-fuel (in continuous line) and sequestration (with black squares) abatement costs with threshold damage function.

\section{Polynomial damage functions}

We start examining polynomial damage functions with the linear case. In this case, marginal damages are positive from the start. And as expected, we now observe a much smoother deforestation pattern: prevention starts as early as in 2000 , and gradually increases, some deforestation still takes place for a few decades. This is shown in Figure 5, where the continuous bold line represents the cumulative deforested area in the business-as-usual scenario, and the line with black squares cumulative deforestation with linear damages. We see that some forest is protected as early as in 2000 , but cumulative deforested area still rises during 20 years along the optimal path: this means that some clearing still takes place, or, in other words, that some carbon is temporary sequestration between periods (about 4 Mha per period).

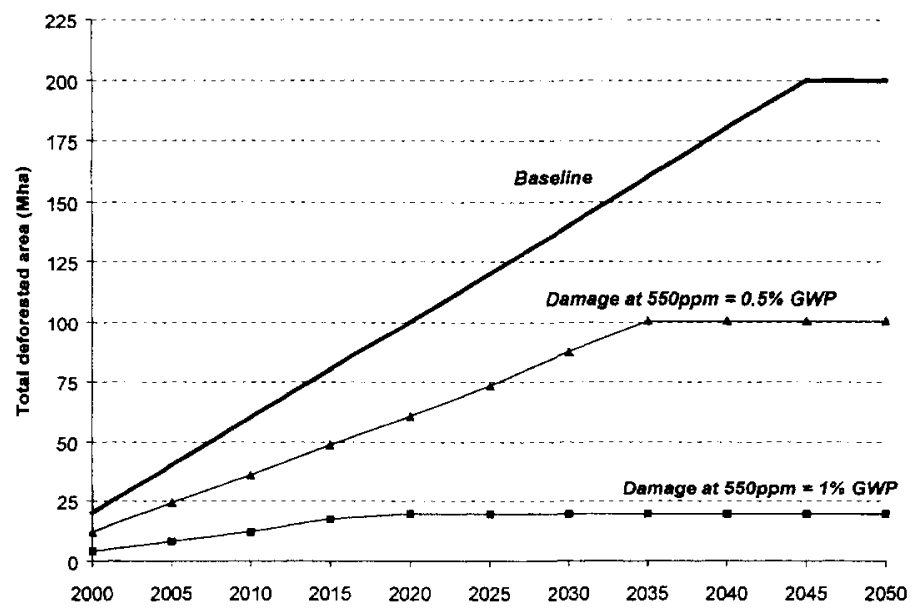

Figure 5: Cumulative deforestation in the baseline scenario (bold line), with linear damages amounting to $0.5 \%$ of Gross World Product if concentration reaches $550 \mathrm{ppm}$ in 2100 (black triangles), and to $1 \%$ of Gross World Product (black squares). 
Figure 6 shows the discounted marginal permanent sequestration costs (black squares) and the marginal fossil fuel abatement costs (continuous line). It confirms that, with linear damage function, marginal damages at low concentration levels are now high enough to trigger decreasing discounted marginal abatement costs. Consequently, marginal (permanent) sequestration costs and marginal abatement costs can now be equated (cf. equation 22), at least until 2020. After 2020 however, we reach the point where the required marginal cost of abatement in the fossil-fuel sector is so great that it exceeds the marginal cost of protecting (forever) all the remaining standing forest. Marginal abatement and sequestration costs thus cannot be equated anymore.

We find this general pattern to be robust to the variation of several parameters (damage levels, discount rates or marginal abatement costs). The surface of forest which is ultimately protected, however, varies significantly with those (as can be seen, for example, in Figure 5 above, where the line with square triangles represent the optimal deforestation path when expected damages when concentration reach 550 ppm are divided by two).

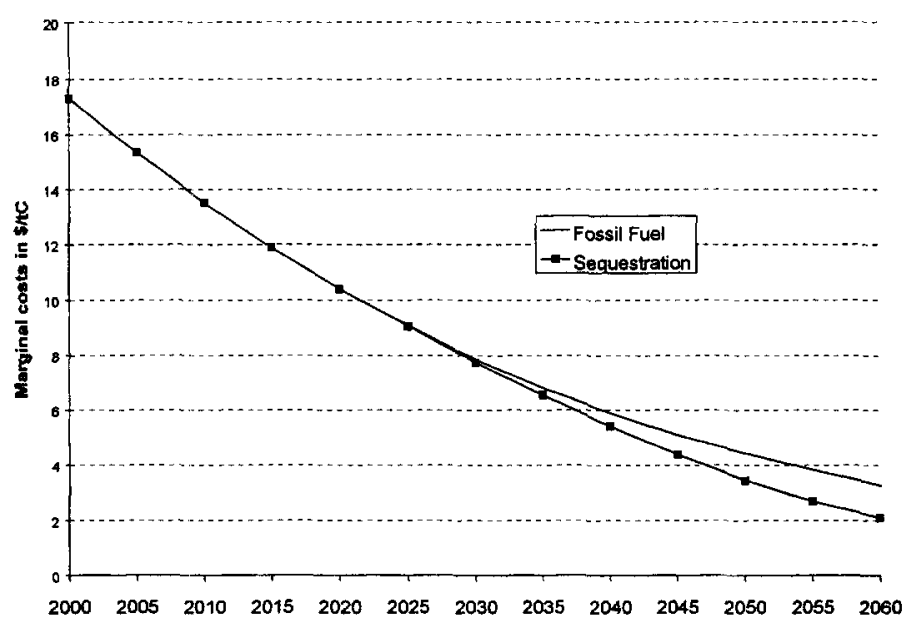

Figure 6: Discounted marginal fossil-fuel (in continuous line) and sequestration (with black squares) abatement costs with linear damage function.

If we move toward damage functions of higher polynomial degrees, we observe a shift towards the "bang-bang" solution. This evolution comes from the fact that, the higher the exponent, the lower marginal damages become at low concentration levels. Figure 7 below illustrates this mechanism. It shows the discounted shadow price of carbon with linear, quadratic and cubic damage functions respectively (the amount of damage at $550 \mathrm{ppm}$ is adjusted to $0.5 \%, 1 \%$ and $1.5 \%$ respectively so as to ensure initial shadow prices are of the same order of magnitude). We see that the discounted the discounted shadow price of carbon decreases from the start in the linear case. On the contrary, it first rises and then curves back with cubic damage functions. The quadratic case is in between, the dynamics of the shadow price of carbon strongly dependent on the value of the other parameters of the model. 


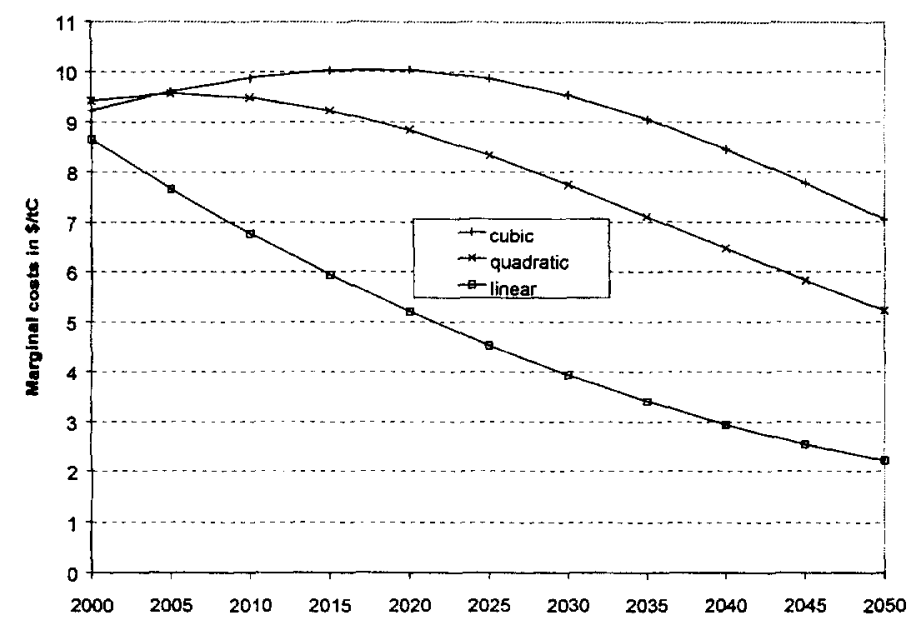

Figure 7: Discounted abatement costs with linear (square), quadratic (triangles) and cubic (crosses) damage functions. Damages at 550 ppm have been set to $0.5 \%, 0.9 \%$ and $1.5 \%$ of World Gross Product respectively so as to ensure similar initial abatement costs.

To sum up these numerical findings, let us take a different angle and assume we have the possibility to undertake a 30-year long sequestration project, knowing that it may not be extended. Under which circumstances should it be undertaken? Previous results show us that:

- If one believes there is limited or no damage at low concentration level (for instance with "threshold" or cubic damage functions), then this 30-year long sequestration project is not costeffective for climate change mitigation, at any positive cost

- On the contrary, if one believes in high marginal damages at low concentration levels (for instance with linear damage function) then the project should be undertaken provided its cost are lower than the gains in terms of price of atmospheric carbon (about $\$ 4.5$ per tons of carbon in the case displayed on Figure 7).

- If one believes in quadratic damage functions, then the project may be undertaken, again provided its costs are less than the gains in terms of price of atmospheric carbon (less than $\$ 2$ per tons of carbon in Figure 7). In this limit case however, the cost-effectiveness of the sequestration project is likely to be strongly dependent on the value of other parameters.

If there was some even some slight chance that the project were to be permanent, then it might still be cost-effective even in the first and third cases. The computation of the expected costs and benefits are, however, beyond the scope of this paper. 


\section{The afforestation case}

In the previous sections, we have focused on deforestation prevention. We now demonstrate that our results still hold when considering afforestation or reforestation activities. In 7.1, we demonstrate that any afforestation activity can be regarded as a combination of elementary projects which are equivalent, as far as emissions is concerned, to deforestation prevention activities. We then exploit this analogy to derive the optimal path of afforestation or reforestation within a global mitigation strategy.

\subsection{Plantations as a combination of elementary sequestration projects}

We consider the case of a tree plantation over a previously non forested area. We assume that this plantation is managed so as to reach as rapidly as possible an equilibrium state where there is an equal number of trees in each age vintage. From this point onward, the forest net emissions are zero as logging is exactly compensated by regrowth. This plantation thus sequesters carbon only during the interim period before the equilibrium is established. Let us denote $p$ the length of this transition in periods, and $\eta_{0}, \eta_{1}, \ldots$, $\eta_{p}$ the incremental quantity of carbon which is sequestered at each period between establishment and equilibrium. We denote $\eta$ the sum of all these coefficients, which represents the carbon density of the plantation at equilibrium.

Let $t_{0}$ be the period at which the plantation is established, and $t_{1}$ be the period at which it is abandoned (we assume the trees are then logged, and all the carbon released in the atmosphere, except if $t_{1}=T$, in which case carbon remains sequestered forever). For simplicity's sake, we also assume that the plantation is abandoned after equilibrium has been reached, i.e. that period $t_{1}$ is posterior to $t_{0}+p$.

The important point here is that the above afforestation project can be regarded as a combination of $p+1$ elementary projects. The first one postpones the emission of $\eta_{0}$ tons of carbon from period $t_{0}$ to period $t_{1}$. The second postpones the emission of $\eta_{1}$ tons of carbon from $t_{0}+1$ to $t_{1}$, etc. And postpones the emission of $\eta_{p}$ tons of carbon from $t_{0}+p$ to $t_{1}$. With regard to the climate, each of these elementary is equivalent to a deforestation prevention project.

As a result, we see that the rules governing the optimal use of afforestation in a global mitigation strategy are similar to those governing deforestation prevention ${ }^{15}$. These rules are detailed in 7.2 below.

\subsection{Insights on the optimal plantation path in a climate strategy}

First, if the plantations are permanent (i.e. $t_{1}=T$, a case similar to the one studied in section 3 ), the optimal use of afforestation is given by (23). The difference with (8) stems from the fact that in the afforestation case, carbon is captured progressively over periods (while in the deforestation prevention case, all the carbon is already there in the trees). Consequently, the weighted sum of future shadow prices of carbon must now be considered.

$$
\mathrm{CL}_{\mathrm{t}}^{\prime}\left(\mathrm{f}_{\mathrm{t}}\right)=\beta \sum_{\mathrm{q}=0}^{\mathrm{p}} \eta_{\mathrm{q}} \lambda_{\mathrm{q}} \theta^{\mathrm{q}}
$$

\footnotetext{
${ }^{15}$ The only difference comes from the combination effect. We do not consider the shadow prices of atmospheric carbon at periods $t_{0}$ and $t_{1}$ anymore, but the difference between the shadow price at period $t_{1}$ and a weighted average of the shadow prices over periods $t_{0}, t_{0}+1, \ldots, t_{0}+p$, with weights precisely equal to the ratio of $\eta_{t} / \eta$ times the discount factor (except if the plantation is cleared before reaching equilibrium, where we consider the weighted average of shadow prices over interval $\left.t_{0}, t_{1}\right)$.
} 
Second, if plantations are temporary (i.e. $\mathrm{t}_{1}<\mathrm{T}$, a case similar to the one studied in section 4 ), marginal sequestration follows rule (24) below. With regard to (13) above, we see that, at equal carbon density per hectare $\eta$, marginal plantation costs should be higher than marginal deforestation prevention costs if the shadow price of carbon rises at a rate higher than the rate of discount between periods $t$ and $t+p$, hence with low marginal damages at low concentration levels. On the other hand, marginal plantation costs should be lower than marginal deforestation prevention costs if marginal damages at low concentration levels are high ${ }^{16}$.

$$
C L_{t}\left(f_{t}\right)=\beta\left[\sum_{q=0}^{p} \eta_{q} \lambda_{q} \theta^{q}-\eta \lambda_{\tau} \theta^{\tau-t}\right]
$$

Let us third consider the optimal forestation path of a unique body of forest where the planner should pay at each period for protecting the plantations, at a price positively correlated with the total afforested area $F_{t}$ (case similar to the one studied in section 5). Again, we obtain two polar sequestration patterns. When the shadow price of atmospheric carbon rises at a rate higher than the rate of discount, optimal plantation is "bang-bang". No forest is planted at first, then, beyond some turning point, plantation starts. On the other hand, if the price of atmospheric carbon rises at a rate lower than the rate of discount, then plantation starts from the start ${ }^{17}$.

\footnotetext{
${ }^{16}$ A difference with deforestation prevention is that, while one cannot prevent prevention on more hectares than it would occur in the baseline, there is a priori no such physical limit to the surface afforested. However, if there is no more need for a constraint similar to 4 , the spatial limitation on the extent of plantations is now embedded into the sequestration cost functions $\mathrm{CL}_{\mathrm{t}}$.

${ }^{17}$ It might be argued, however, that the model of section 5 should not be transposed to plantation. Contrary to deforestation prevention, plantations may indeed generate internal revenues and become sustainable in the long run (the role of the planner being simply to help starting the project by funding establishment costs for instance). This may actually be true also for deforestation prevention. For example, households could be provided with alternative job opportunities which generate revenues and become sustainable in the long run.

Nevertheless, beyond some limit, it appears difficult to discard the possibility that global land scarcity might trigger increasing land-use competition and therefore raise sequestration costs. To put it another way, behind any model which assumes sequestration costs depend only on the incremental surface forested stands the implicit but necessary assumption that the total supply of land for sequestration available over all periods is below some kind of acceptability limit beyond which competition for land-use would become too fierce.
} 


\section{Conclusion}

How should the risk of non permanence affect decision about carbon sequestration? The long-term climate policy optimization model we have developed in this paper yields three main insights on this question:

- When permanence can be guaranteed, sequestration is equivalent to abatement from fossil fuel combustion. Where it is impossible to guarantee permanence of individual projects, it may be possible to apply the same reasoning to portfolios of projects, adjusted for the expected proportion of nonpermanent projects.

- Explicit contracts for temporary sequestration, on the other hand, make sense only when the rationale for mitigation is reduction of damages, and current marginal damages of climate change are thought to be significant: sequestration is then cost-effective because it postpone damages. In this case, there's a rationale to begin temporary sequestration contracts immediately, and they will probably be renewed indefinitely.

- Such temporary sequestration contracts also make sense when the rationale for mitigation is keeping concentration below some threshold, but only when concentrations are approaching that threshold. Here the sequestration project serves to bridge the "hump" of high energy abatement costs. Under this rationale, sequestration follows a "bang-bang" optimal dynamics, and begins immediately only if the goal is to stabilize at very low concentration levels.

Our analysis thus limits the scope of the "buying time" argument for temporary sequestration. We see in particular that the key parameter for the dynamics of sequestration is the shape of the climate change damage function, and not the expectations about technical change. One would have to be extremely optimistic about diffusion of non-carbon energy technologies over the next few decades to justify current sequestration as a bridge to these technologies.

However, this analysis does not rule out the usefulness of temporary sequestration projects on broader grounds. First, in the Kyoto context, it may make sense to bundle temporary sequestration projects with follow-on permanent abatement projects, depending on the expected-price path of carbon - which will depend on the rules governing each successive commitment period - and the acceptability of this proposal under the Protocol (Chomitz 2000). Secondly, temporary sequestration projects may be justifiable if they have a nonzero chance of bringing about permanent change, e.g. by diffusing more carbon-absorbing land management practices. Third, one could also imagine policies that substituted cheap temporary sequestration for more expensive energy-based abatement, and invested the savings in research and development on carbon mitigation technologies. A model where technical change is endogenous would be necessary to examine this question. Last, if we drop our assumption that the planner operates with full knowledge of future baselines, climate change impacts and technologies, temporary sequestration projects might have a value in saving time to gain information. These are areas for future research.

\section{Acknowledgements}

The authors would like to thank Maureen Cropper, Alain Karsenty, Timothy Thomas, Vincent Gitz, and Philippe Ambrosi for valuable comments on this paper. They have also greatly benefited from discussions with Gunnar Eskeland. Remaining errors are of course the authors' sole responsibility. 


\section{References}

Bolin B., Sukumar R., Ciais P., Cramer W., Jarvis P., Kheshgi H., Nobre C., Semenov S., Steffen W. [2000] Global perspective, in Watson et al. (chapter 1), pp.23-52.

Broecker W.S. [1997] Thermohaline circulation, the Achilles heel of our climate system: will man-made $\mathrm{CO}_{2}$ upset the current balance?, Science Vol.278, 1582-1588.

Chomitz K. [2000] Evaluating carbon offsets from forestry and energy projects: how do they compare?, World Bank Policy Research Working Paper 2315, World Bank Development Research Group, Washington, 25p.

Dixon R.K., Brown, S., Houghton R.A., Salomon A.M., Trexler M.C., Wisniewski J. [1994] Carbon pools and flux of global forest ecosystems, Science Vol.263, 185-190.

FAO [2000a] Agriculture: towards 2015/2030 - Global Interim Report, Global Perspective Studies Unit, Rome, 240p.

FAO [2000b] Forest Resource Assessment, available online at www.fao.org/forestry, accessed January 12, 2001.

Houghton R.A., Skole D.L., Nobre C.A., Hackler J.L., Lawrence K.T., Chomentowski W.H. [2000] Annual fluxes of carbon from deforestation and regrowth in the Brazilian Amazon, Nature Vol.403, 301-304.

IEA [2000] $\mathrm{CO}_{2}$ emissions from fuel combustion 1971-1998, IEA-OECD, Paris, 530p.

Joos F., Müller-Fürstenberg G., Stephan G. [1999] Correcting the carbon cycle: how important is it for the economics of climate change?, Environmental Modeling and Assessment 4(2/3), 133-140.

Kattenberg A., Giorgi F., Grassi A., Meehl G.A., Mitchell J.F.B., Stouffer R.J., Tokioka T., Weaver A.J., Wigley T.M.L. (lead authors) [1996] Climate models - Projections of future climate, in Houghton J.T., Meira Filho L.G., Callander B.A., Harris N., Kattenberg A., Maskell K. (Eds.) Climate change 1995, the science of climate change, contribution of the WGI to the Second Assessment Report of the Intergovernmental Panel on Climate Change (chapter 6), Cambridge University Press, Cambridge, pp.285-358.

Keeling C.D., Whorf T.P. [2000] Atmospheric $\mathrm{CO} 2$ records from sites in the SIO air sampling network, in Trends: A Compendium of Data on Global Change, Carbon Dioxide Information Analysis Center, Oak Ridge National Laboratory, U.S. Department of Energy, Oak Ridge.

Leggett J., Pepper W.J., Swart R.J., Edmonds J.A., Meira Filho L.G., Mintzer I., Wang M.-X., Wasson J. [1992] Emission scenarios for IPCC: an update, in Houghton J.T., Callander B.A., Varney S.K. (Eds.) Climate change 1992: the supplementary report to the IPCC scientific assessment, Cambridge University Press, Cambridge, pp.69-96.

Morita T., Lee H.-S. [1997] Emission scenario database prepared for IPCC Special Report on Emission Scenarios, available online at http://sres.ciesin.org/index.html, accessed January 15, 2001.

Nakicenović N., Swart R. (Eds.) [2000] Special Report on Emissions Scenarios, Intergovernmental Panel on Climate Change, Cambridge University Press, Cambridge, 570p.

Noble I., Scholes R.J. [2001] Sinks and the Kyoto Protocol, Climate Policy 1(1), 5-25. 
Nordhaus W.D. [1992] An optimal transition path for controlling greenhouse gases, Science Vol.258, 1315-1318.

Parry M., Rosenzweig C., Iglesias A., Fischer G., Livermore M. [1999] Climate change and the world food security: a new assessment, Global Environmental Change 9 (supplementary issue), S51-S67.

Sampson R.N., Scholes R.J., Cerri C., Erda L., Hall D.O., Handa M., Hill P., Howden M., Janzen H., Kimble J., Lal R., Marland G., Minami K., Paustian K., Read P., Sanchez P.A., Scoppa C., Solberg B., Trossero M.A., Trumbore S., Van Cleemput O., Whitmore A., Xu D. [2000] Additional human-induced activities - Article 3.4, in Watson et al. (chapter 4), pp.181-282.

Schwarze R., Niles J.O. [2000] The long-term requirement for clean development mechanism forestry and economic liability, Journal of Environment and Development 9(4), 384-404.

Streets D.G., Glantz M.H. [2000] Exploring the concept of climate surprise, Global Environmental Change 10(2), 97-107.

Svirezhev Y., Brovkin V., Von Bloh W., Schellnhuber H.J., Petschel-Held G. [1999] Optimisation of reduction of global $\mathrm{CO}_{2}$ emission based on a simple model of the carbon cycle, Environmental Modeling and Assessment 4(1), 23-33.

Tol R.S.J., Fankhauser S. [1998] On the representation of impacts in integrated assessment models of climate change, Environmental Modeling and Assessment 3(1/2), 63-74.

Vincent J.R., Mohamed Ali R., Tan X.Y., Yahara J., Abdul Rahim K., Teck Ghee L., Meyer A.S., Haji Othman M.S., Sivalingam G. [1997] Environment and development in a resource-rich economy: Malaysia under the new economic policy, Harvard University Press, Harvard, 419p.

Watson R.T., Noble I.R., Bolin B., Ravindranath N.H., Verardo D.J., Dokken D.J. [2000] Land use, land-use change and forestry, Special report of the Intergovernmental Panel on Climate Change, Cambridge University Press, Cambridge, 377p. 


\section{Annex 1: Optimal climate policy with permanent sequestration}

The Lagrangian for problem (1)-(7) is given below. $\kappa_{\mathrm{t}}, \sigma_{\mathrm{t}}, \chi_{\mathrm{t}}, \xi_{\mathrm{t}}$ and $\lambda_{\mathrm{t}}$ are Lagrange multipliers associated with constraints (1), (2), (3), (4) and (6) respectively. $\lambda_{t}$ can be interpreted as the spot shadow price of atmospheric carbon ${ }^{18}$.

$$
\begin{aligned}
\mathbf{L}= & -\sum_{t=0}^{T}\left[C_{t}\left(a_{t}\right)+C L_{t}\left(f_{t}\right)+D_{t}\left(M_{t}\right)\right] \theta^{t}+\sum_{t=0}^{T-1} \lambda_{t} \theta^{t}\left[M_{t+1}-(1-\delta) M_{t}-\beta\left(e_{t}+e_{t}-a_{t}-\eta f_{t}\right)\right] \\
& +\sum_{t=0}^{T} \kappa_{t} \theta^{t} a_{t}+\sum_{t=0}^{T} \sigma_{t} \theta^{t}\left(e_{t}-a_{t}\right)+\sum_{t=0}^{T} \chi_{t} \theta^{t} f_{t}+\sum_{t=0}^{T} \xi_{t} \theta^{t}\left(d_{t}-f_{t}\right)
\end{aligned}
$$

First order conditions for problem are as follows. First, Lagrange multipliers $\kappa_{t}, \sigma_{t}, \chi_{t}$ and $\xi_{t}$ associated with inequality constraints are positive or zero, and strictly positive only if the corresponding constraint is binding. Second, partial derivatives of the Lagrangian with respect to all variables are zero.

Let us start by fossil-fuel abatement. Equation (a2) states that along the optimal path, when the abatement is strictly positive but does not offset all the emissions, i.e. when Langrange multipliers $\kappa_{t}$ and $\sigma_{t}$ are zero, marginal abatement costs are equal to the shadow price of carbon scaled down by parameter $\beta$ to take into account instantaneous carbon uptake. There is of course no incentive to abate during the last period $\mathrm{T}(\mathrm{a} 3)^{19}$. We come back to this border effect below.

$$
\begin{array}{llll}
\frac{\partial \mathbf{L}}{\partial \mathbf{a}_{\mathrm{t}}}=0 & \Rightarrow & \mathrm{C}_{\mathrm{t}}^{\prime}\left(\mathrm{a}_{\mathrm{t}}\right)=\lambda_{\mathrm{t}} \beta+\left(\kappa_{\mathrm{t}}-\sigma_{\mathrm{t}}\right) & \\
\frac{\partial \mathbf{L}}{\partial \mathrm{a}_{\mathrm{T}}}=0 & \Rightarrow & \mathrm{C}_{\mathrm{T}}^{\prime}\left(\mathrm{a}_{\mathrm{T}}\right)=\kappa_{\mathrm{T}}-\sigma_{\mathrm{T}} \quad \Rightarrow & \text { for } 0 \leq \mathrm{a} \leq \mathrm{a}-1 \\
\mathrm{a}=0 & &
\end{array}
$$

Marginal sequestration costs follow exactly the same conditions (a4-a5). The average carbon content per hectare $\eta$ in equation (a4) simply translates costs of carbon (in monetary unit per quantity of carbon) into costs of land (in monetary unit per surface of land). Eliminating $\lambda_{t}$ in equations (a2) and (a4) and assuming none of the constraints is binding yield equalization of marginal abatement costs and marginal sequestration costs (8).

$$
\begin{array}{lll}
\frac{\partial \mathbf{L}}{\partial \mathrm{f}_{\mathrm{t}}}=0 \quad & \Rightarrow \quad \mathrm{CL}_{\mathrm{t}}\left(\mathrm{f}_{\mathrm{t}}\right)=\lambda_{\mathrm{t}} \eta \beta+\left(\chi_{\mathrm{t}}-\xi_{\mathrm{t}}\right) \quad \text { for } 0 \leq \mathrm{t} \leq \mathrm{T}-1 \\
\frac{\partial \mathbf{L}}{\partial \mathrm{f}_{\mathrm{T}}}=0 \quad \Rightarrow \quad \mathrm{CL}_{\mathrm{T}}\left(\mathrm{f}_{\mathrm{T}}\right)=\chi_{\mathrm{T}}-\xi_{\mathrm{T}} \quad \Rightarrow \mathrm{f}_{\mathrm{T}}=0 &
\end{array}
$$

The dynamics of model (1)-(7) is therefore governed by the variations of the shadow price of atmospheric carbon $\lambda_{t}$ given in (a6) and (a7) below. By backward induction, equations (a6) and (a7) define a unique trajectory of carbon price, which in turns define a unique trajectory of abatement and sequestration.

\footnotetext{
${ }^{18}$ It would have been possible in theory to eliminate concentration from the objective function by replacing $M_{1}$ with its value, a function of $a_{0}, \ldots, a_{t-1}$ and $f_{0}, \ldots, f_{t-1}$. We avoid this fastidious operation by considering $M_{t}(1 \leq t \leq T)$ as variables constrained by the carbon cycle (6).

${ }^{19}$ By definition of Lagrange multipliers, $\kappa_{\mathrm{T}} \mathrm{a}_{\mathrm{T}}=0$ and $\sigma_{\mathrm{T}} \geq 0$. If $\mathrm{a}_{\mathrm{T}}$ were strictly positive, then $\kappa_{\mathrm{T}}$ would be zero. By equation (a3), we would then have negative marginal abatement costs, which is impossible by definition of functions $C_{t}$. Consequently, $a_{\mathrm{T}}=0$.
} 


$$
\begin{aligned}
& \frac{\partial \mathbf{L}}{\partial \mathrm{M}_{\mathrm{t}}}=0 \Rightarrow \lambda_{\mathrm{t}}=\frac{\lambda_{\mathrm{t}-1}}{\theta(1-\delta)}-\frac{\mathrm{D}_{\mathrm{t}}^{\prime}\left(\mathrm{M}_{\mathrm{t}}\right)}{1-\delta} \Leftrightarrow \lambda_{\mathrm{t}-1}=\theta(1-\delta) \lambda_{\mathrm{t}}+\theta \mathrm{D}_{\mathrm{t}}^{\prime}\left(\mathrm{M}_{\mathrm{t}}\right)(1 \leq \mathrm{t} \leq \mathrm{T}-1) \\
& \frac{\partial \mathbf{L}}{\partial \mathrm{M}_{\mathrm{T}}}=0 \quad \Rightarrow \quad \lambda_{\mathrm{T}-1}=\mathrm{D}_{\mathrm{T}}^{\prime}\left(\mathrm{M}_{\mathrm{T}}\right) \theta
\end{aligned}
$$

As indicated in 2.4, we choose $\mathrm{T}$ so that concentration at this period is back to current level even in the baseline emission scenario. Any abatement prior to this date will only make concentration come back to its current level more rapidly. As we also assumed marginal damages would be lower than current marginal damages, we obtain that the discounted shadow price of carbon is (far) lower at period T-1 than it is today, i.e. $\theta^{\mathrm{T}-1} \lambda_{\mathrm{T}-1}<\lambda_{0}$ (see footnote 13 ). Consequently, the discounted shadow price of carbon will eventually start decreasing at some future point of time.

\section{Annex 2: Optimal climate policy with temporary sequestration}

Using the same notations as in annex 1 , the Lagrangian for problem $(1,2,3,4,6,7,10,11)$ is:

$$
\begin{aligned}
& \mathbf{L}=-\sum_{t=0}^{T}\left[C_{t}\left(a_{t}\right)+C L_{t}\left(f_{t}\right)+D_{t}\left(M_{t}\right)\right] \theta^{t}+\sum_{t=0}^{\tau-1} \lambda_{t} \theta^{t}\left[M_{t+1}-(1-\delta) M_{t}-\beta\left(e_{t}+e l_{t}-a_{t}-\eta f_{t}\right)\right] \\
& +\sum_{t=\tau}^{T-1} \lambda_{t} \theta^{t}\left[M_{t+1}-(1-\delta) M_{t}-\beta\left(e_{t}+e l_{t}-a_{t}-\eta f_{t}+\eta f_{t-\tau}\right)\right] \\
& +\sum_{t=0}^{T} \kappa_{t} \theta^{t} a_{t}+\sum_{t=0}^{T} \sigma_{t} \theta^{t}\left(e_{t}-a_{t}\right)+\sum_{t=0}^{T} \chi_{t} \theta^{t} f_{t}+\sum_{t=0}^{T} \xi_{t} \theta^{t}\left(d_{t}-f_{t}\right)
\end{aligned}
$$

First order conditions are identical to the ones obtained in annex 1 above, with the exception of partial derivatives with regard to $f_{t}$, which now assume three different expressions depending on the value of $t$. Like (a5) above, equation (a11) simply translates the fact that there is no incentive to act at the last period. For the $\tau$ preceding periods, sequestration appears "permanent" for the planner, as carbon would only be released beyond horizon $T$. The first order equation governing sequestration for these last periods (a10) is therefore identical to the one obtained in the permanent sequestration case (a4).

$$
\begin{array}{llll}
\frac{\partial \mathbf{L}}{\partial \mathrm{f}_{t}}=0 & \Rightarrow & \mathrm{CL}_{\mathrm{t}}\left(\mathrm{f}_{\mathrm{t}}\right)=\left(\lambda_{\mathrm{t}}-\lambda_{\mathrm{t}+\tau} \theta^{\tau}\right) \eta \beta+\left(\chi_{\mathrm{t}}-\xi_{\mathrm{t}}\right) & \text { for } 0 \leq \mathrm{t} \leq \mathrm{T}-\tau-1 \\
\frac{\partial \mathbf{L}}{\partial \mathrm{f}_{\mathrm{t}}}=0 & \Rightarrow & \mathrm{CL}_{\mathrm{t}}\left(\mathrm{f}_{\mathrm{t}}\right)=\lambda_{\mathrm{t}} \eta \beta+\left(\chi_{\mathrm{t}}-\xi_{\mathrm{t}}\right) & \\
\frac{\partial \mathbf{L}}{\partial \mathrm{f}_{\mathrm{T}}}=0 & \Rightarrow & \operatorname{CLL}_{\mathrm{T}}\left(\mathrm{f}_{\mathrm{T}}\right)=\chi_{\mathrm{T}}-\xi_{\mathrm{T}} \quad \Rightarrow \quad \mathrm{f}_{\mathrm{T}}=0 &
\end{array}
$$

The results given in section 4 follow. Indeed, for all periods before $T-\tau$, which constitute most of the periods if we assume $T$ to be large and $\tau$ to be small with regard to $T$, the optimal use of sequestration depend on the difference between the discounted value of carbon when it is sequestered and when it is released (equation a9). Precisely, if $\lambda_{t}-\lambda_{t+\tau} \theta^{\tau} \leq 0-$ i.e. if the shadow price of carbon grows at a rate higher than the rate of discount between periods $t$ and $t+\tau-$ then $\chi_{t}$ must become strictly positive to ensure that marginal sequestration costs do not become negative. Which means, by definition of Lagrange multiplier $\chi$, that $\mathrm{f}_{\mathrm{t}}=0$ : no sequestration is undertaken. On the contrary, if $\lambda_{t}-\lambda_{t+\tau} \theta^{\tau}>0-$ i.e. if the shadow 
value of atmospheric carbon grows at a rate lower than the rate of discount between $t$ and $t+\tau-$ then $f_{t}$ becomes positive: temporary sequestration is used along the optimal path. This distinction is straightforward: temporary sequestering carbon is indeed cost-effective if and only if, at the margin, the value of one ton emitted later is lower (in discounted terms) than the value of one ton emitted now.

\section{Annex 3: Optimal climate policy with both permanent and temporary sequestration}

The Lagrangian for problem $(1,2,3,5,6,18,19,20)$ is given below. Lagrange multipliers $\chi_{\mathrm{t}}$ are associated with constraints (19).

$$
\begin{aligned}
& \mathbf{L}=-\sum_{t=0}^{T}\left[C_{t}\left(a_{t}\right)+C L_{t}\left(\sum_{q=0}^{t} f_{q}\right)+D_{t}\left(M_{t}\right)\right] \theta^{t}+\sum_{t=0}^{T-1} \lambda_{t} \theta^{t}\left[M_{t+1}-(1-\delta) M_{t}-\beta\left(e_{t}+e l_{t}-a_{t}-\eta f_{t}\right)\right] \\
& +\sum_{t=0}^{T} \kappa_{t} \theta^{t} a_{t}+\sum_{t=0}^{T} \sigma_{t} \theta^{t}\left(e_{t}-a_{t}\right)+\sum_{t=0}^{T} \chi_{t} \theta^{t} \cdot\left(\sum_{q=0}^{t} f_{q}\right)+\sum_{t=0}^{T} \xi_{t} \theta^{t}\left(d_{t}-f_{t}\right)
\end{aligned}
$$

First order conditions are again identical to the ones obtained in the permanent sequestration case, with exception of the derivatives relative to the amount of land preserved from deforestation $f_{t}$.

$$
\begin{aligned}
& \frac{\partial \mathbf{L}}{\partial \mathrm{f}_{\mathrm{t}}}=0 \quad \Rightarrow \quad \sum_{\mathrm{q}=\mathrm{t}}^{\mathrm{T}} \mathrm{CL}_{\mathrm{q}}^{\prime}\left(\mathrm{F}_{\mathrm{q}}\right) \theta^{\mathrm{q}-\mathrm{t}}=\lambda_{\mathrm{t}} \eta \beta+\left[\sum_{\mathrm{q}=\mathrm{t}}^{\mathrm{T}} \chi_{\mathrm{q}} \theta^{\mathrm{q}-\mathrm{t}}-\xi_{\mathrm{t}}\right] \quad \text { for } 0 \leq \mathrm{t} \leq \mathrm{T}-1 \\
& \frac{\partial \mathbf{L}}{\partial \mathrm{f}_{\mathrm{T}}}=0 \quad \Rightarrow \quad \mathrm{CL}_{\mathrm{T}}\left(\mathrm{f}_{\mathrm{T}}\right)=\chi_{\mathrm{T}}-\xi_{\mathrm{T}} \quad \Rightarrow \quad \mathrm{f}_{\mathrm{T}}=0
\end{aligned}
$$

The dynamics of sequestration is governed by equation (a13) which states that, when constraints (3) and (4) are not binding, the marginal cost of protecting one additional hectare of forest at each period from period $t$ to horizon $\mathrm{T}$ - that is the marginal cost of permanent sequestration - should be equal to the shadow price of carbon (weighted by $\beta$ and by the carbon per hectare ratio $\eta$ ). Again, the dynamics of sequestration depends on whether the shadow price of carbon grows at a rate higher or lower than the discount rate, which can be seen by "differentiating" equation (a13).

$$
\mathrm{CL}_{\mathrm{t}}^{\prime}\left(\mathrm{F}_{\mathrm{t}}\right)=\left(\lambda_{\mathrm{t}}-\theta \lambda_{\mathrm{t}+1}\right) \eta \beta+\chi_{\mathrm{t}}+\left[\xi_{\mathrm{t}+1} \theta-\xi_{\mathrm{t}}\right]
$$

What does this equation imply for the evolution of sequestration? Let us first assume that $\lambda_{t}$ grows at a rate strictly higher than the rate of discount between periods $t$ and $t+1$ (i.e. that $\lambda_{1}-\theta \lambda_{t+1}<0$ ). Under this assumption, equation (a15) requires the term $\chi_{\mathrm{t}}+\left[\xi_{\mathrm{t}+1} \theta-\xi_{\mathrm{t}}\right]$ to be strictly positive, which occurs in two cases:

(i) $\xi_{t+1}=0$ and $\chi_{P}>0$, that is when no forest is protected at all at period $t\left(F_{t}=0\right.$, which implies $\left.\chi_{p}>0^{20}\right)$ and when not all forest is protected at period $t+1\left(f_{t+1}<d_{t+1}\right.$, which implies $\left.\xi_{t+1}=0\right)$.

(ii) $\xi_{t+1} \cdot \theta-\xi_{p}>0$, that is when all possible forest is protected at period $t+1\left(f_{t+1}=d_{t+1}\right.$, which implies $\xi_{t+1}=0$ ). Note that in this case, we have obviously $\chi_{t+1}=0$, which implies that for equation (a15) to hold at time $t+1$, it is necessary that $\xi_{t+2} \theta-\xi_{t+1}>0$.

Rules (i) and (ii) define the dynamics of $\lambda_{1}$ for the period where the shadow price of carbon grows at a rate strictly higher than the rate of discount. Three evolutions are indeed possible:

\footnotetext{
${ }^{20}$ The fact that no forest at all is protected at period $t$ obviously implies that the incremental amount of forest protected at period $t$ is zero $\left(f_{t}=0\right)$. Hence $f_{t}<d_{t}$ and $\xi_{t}=0$.
} 
- no sequestration at all along this period $\left(f_{t}=0\right.$ all along the period): we are always in case (i).

- some sequestration at first period $\left(f_{0}>0\right)$ and full sequestration from period 1 onward: we are in case (ii) from the start.

- or no sequestration until period $\underline{t}\left(f_{t}=0\right.$ for all $\left.t<t\right)$, and full after period $\underline{t}\left(f_{t}=d_{t}\right.$ for all $\left.t>t\right)$ : we are in case (i) until period t-1 and in case (ii) afterwards.

Now when the shadow price of carbon starts growing less rapidly than the rate of discount (which we know it will eventually), i.e. when $\lambda_{t}-\theta \lambda_{t+1}>0$, it is necessary that there is some sequestration for equation (a15) to hold (if indeed $F_{t}$ were zero, the left hand side of the equation would be zero, while the right hand side would be strictly positive). Whether there is full sequestration or not, i.e. whether constraint (19) is binding depends on the supply of forest, of the marginal sequestration costs, and on the speed at which discounted price of atmospheric carbon diminishes. 



\section{Policy Research Working Paper Series}

Title

WPS2615 Trade, Growth, and Poverty

WPS2616 Reforming Land and Real Estate Markets

WPS2617 Shanghai Rising in a Globalizing World

WPS2618 Globalization and the Challenge for Developing Countries

WPS2619 Do Banks Provision for Bad Loans in Good Times? Empirical Evidence and Policy Implications

WPS2620 Who Owns the Media?

WPS2621 Does Indonesia Have a "Low-Pay" Civil Service?

WPS2622 Community Programs and Women's Participation: The Chinese Experience $x$
WPS 2623 Trade Liberalization in China's Accession to the World Trade Organization
Author

David Dollar

Aart Kraay

Ahmed Galal

Omar Razzaz

Shahid Yusuf

Weiping Wu

Shahid Yusuf

Michele Cavallo

Giovanni Majnoni

Simeon Djankov

Caralee McLiesh

Tatiana Nenova

Andrei Shleifer

Deon Filmer

David L. Lindauer

David Coady

Xinyi Dai

Limin Wang

Date

June 2001

June 2001

June 2001

June 2001

June 2001

Elena lanchovichina Will Martin

June 2001

June 2001

June 2001

June 2001
Contact

for paper

E. Khine 37471

D. Dietrich 34995

S. Yusuf 82339

S. Yusuf 82339

E. Mekhova 85986

R. Sugui 37951
June 2001

H. Sladovich 37698

June 2001

L. Tabada 36896

June 2001

Donna Maclsaac Martín Rama

June 2001

H. Sladovich 37698

L. Wang 37596

L. Tabada 36896

Harold Alderman

Jesko Hentschel Ricardo Sabates
Externalities in the Production of Nutrition in Peru 


\section{Policy Research Working Paper Series}

Title

WPS2628 Monopoly Power and Distribution in Fragmented Markets: The Case of Groundwater

WPS2629 Bridging the Digital Divide: How Enterprise Ownership and Foreign Competition Affect Internet Access in Eastern Europe and Central Asia

WPS2630 Parallel Imports of Pharmaceutical Products in the European Union

WPS2631 Pension Reform in Hungary: A Preliminary Assessment

WPS2632 Human Capital and Growth: The Recovered Role of Education Systems

WPS2633 Bank Privatization in Argentina: A Model of Political Constraints and Differential Outcomes

WPS2634 Chile's Regional Arrangements and the Free Trade Agreement of the Americas: The Importance of Market Access

\section{Author}

Date

Hanan G. Jacoby

Rinku Murgai

Saeed Ur Rehman

George R. G. Clarke

July 2001

Mattias Ganslandt

Roberta Rocha

Dimitri Vittas

Sébastien Dessus

George R. G. Clarke

Robert Cull

Glenn W. Harrison

Thomas F. Rutherford

David G. Tarr

July 2001

July 2001

July 2001

July 2001

July 2001
Contact for paper

June 2001

P. Kokila

33716

P. Sintim-Aboagye 37644

L. Tabada 36896

L. Gross

37030

K. Mazo

39744

P. Sintim-Aboagye 37644

L. Tabada 36896 